\title{
Effect of glitazones on the progression of coronary artery disease in type 2 diabetes patients
}

\author{
This article was published in the following Dove Press journal: \\ Vascular Health and Risk Management \\ 22 December 2009 \\ Number of times this article has been viewed
}

\author{
Jamison Wyatt' \\ Shailesh Nandish' \\ Rene Oliveros' \\ Adrienne S Zion ${ }^{2}$ \\ Michael S Lujan' \\ Robert Chilton' \\ 'University of Texas Health Science \\ Center, San Antonio, Texas, USA; \\ ${ }^{2}$ Columbia University's Teachers \\ College, New York, NY, USA
}

Correspondence: Robert Chilton Professor of Medicine, University of Texas Health Science Center, San Antonio, Texas 7826I, USA

Tel +I 210567460I

Email chiltonr@gmail.com

\begin{abstract}
The effect of thiazolidinediones (TZDs) on the progression of atherosclerosis in diabetes patients remains unclear. There has been heightened interest in recent years in this class of diabetes medications due to the non-glycemic lowering effects, such as altering lipids, inflammation and hematologic profiles. There have been several exciting studies over the past few years focused on the mechanism of action of the TZDs with respect to alteration in the cardio-metabolic profile in diabetes patients. New tools such as intravascular ultrasound have been used to follow plaques characteristics over time on a much more sensitive scale than has ever been possible in the past by coronary angiograms. These advances have enabled researchers to follow closely the macrovascular effects of different anti-atherosclerotic medications such as statins and TZDs. This article reviews the pathophysiology of atherosclerosis in diabetes, the role that TZDs play in this process and the imaging trials looking at the progression or regression of atherosclerosis in patients treated with TZDs.
\end{abstract}

Keywords: thiazolidinediones, atherosclerosis, diabetes

\section{Introduction}

The purpose of this review is to address many of the controversies surrounding the affects of glitazones and coronary atherosclerosis. The impact of thiazolidinediones (TZDs) and their ability to alter the progression of atherosclerosis in diabetics remains unclear. As the prevalence of diabetes increases, the burden of atherosclerosis is increasing at an alarming rate. The Center for Disease Control (CDC) now projects that by 2050 nearly 50 million people will be diagnosed with diabetes, up from their prior estimate of 39 million released just 2 years earlier. The largest impact will be seen in minority groups, with an expected increase of $481 \%$ in Hispanics and 208\% in blacks. ${ }^{1}$ An analysis of the Framingham Heart Study by Fox et al demonstrated that the lifetime risk for cardiovascular disease is increased among individuals with obesity and diabetes, with a $78.8 \%$ lifetime risk in women and an $86.9 \%$ risk in men. ${ }^{2}$ Overall, obesity alone was found to carry an additional $20 \%$ risk for the development of cardiovascular disease (CVD), compared to normal weight individuals. Prior studies have estimated that the lifetime risk of diabetes increases in proportion to BMI, ranging from $7.6 \%$ among underweight individuals to as high as $74.4 \%$ among individuals with stage 2 obesity $^{3}$ (Figure 1).

Patients with diabetes have a significant increase in the risk of advanced cardiovascular disease. Over a period of 18 years, Juutilainen et al studied 2301 patients with and without diabetes who were all free of CVD at baseline. ${ }^{4} 50 \%$ of subjects with type 1 diabetes, $68 \%$ of subjects with type 2 diabetes, and $19 \%$ of nondiabetes subjects submit your manuscript | www.dovepress.com

Dovepress
Vascular Health and Risk Management 2010:6 I-8

(C) 2010Wyatt et al publisher and licensee Dove Medical Press Ltd. This is an Open Access article which permits unrestricted noncommercial use, provided the original work is properly cited. 


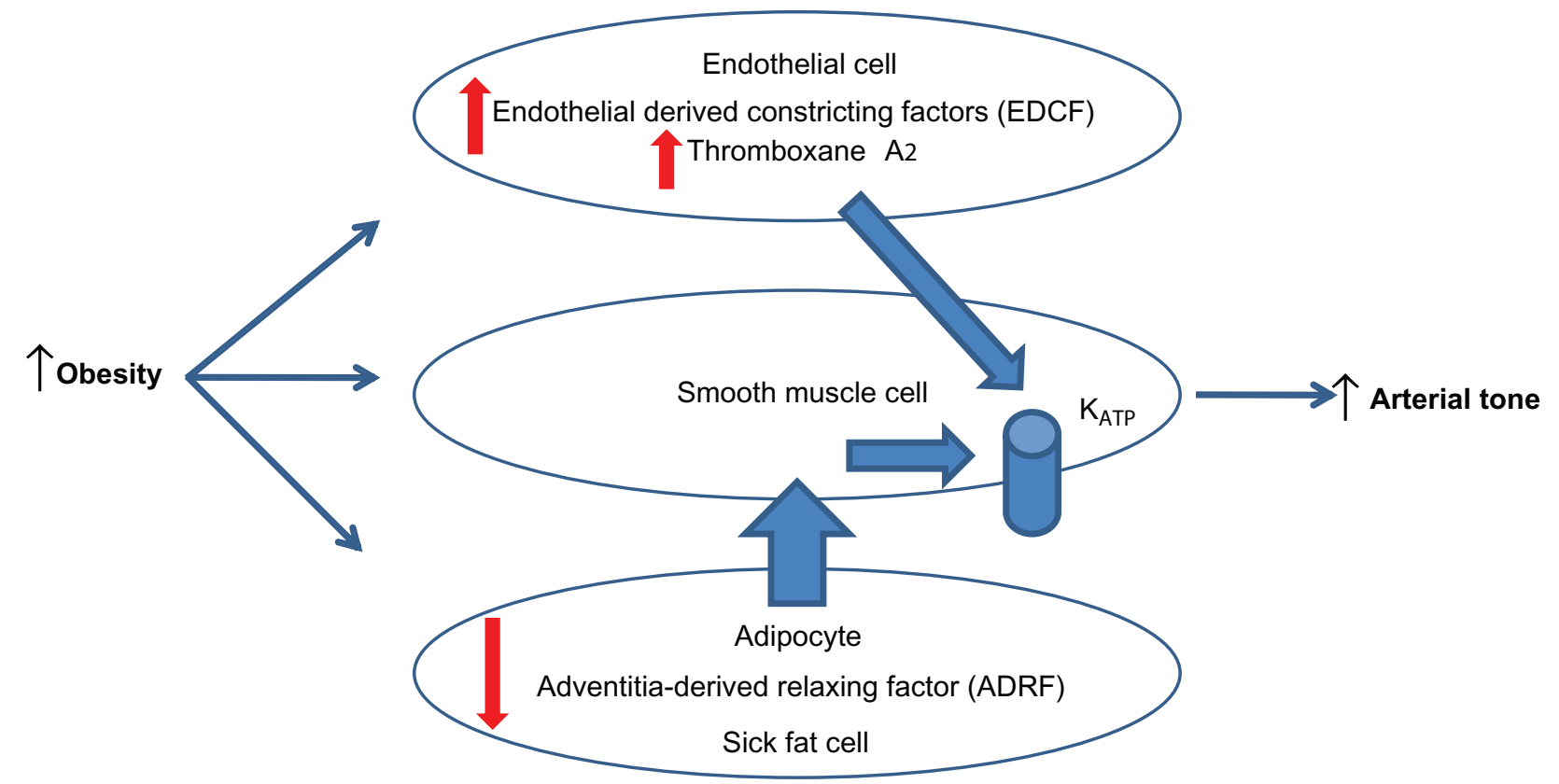

Figure I Endothelial dysfunction-obesity hypothesis. ${ }^{10}$

died during the follow-up period. The adjusted hazard ratio for type 1 diabetics vs nondiabetics was 3.6 (95\% CI 2.2-5.7) in men and 13.3 (95\% CI 6.9-22.5) in women. For type 2 diabetics vs nondiabetics, the adjusted hazard ratio was 3.3 (95\% CI 2.5-4.5) in men and 10.1 (95\% CI 6.7-17.4) in women. Similar results were found by the Renfrew Paisley survey with 25 years of follow-up of 15,406 patients. ${ }^{5}$ Goraya et al in a population based autopsy study, noted similar cardiovascular autopsy findings in non-diabetes patients with known ischemic heart disease compared to diabetes patients with no known ischemic heart disease, further emphasizing the role of diabetes as a coronary artery disease risk factor equivalent. $^{6}$

Given these findings, there has been much interest in altering the inherent $\mathrm{CV}$ risk in diabetics through alteration of their metabolic profile. TZDs have been of particular interest due to the recognized pleiotrophic effects above and beyond lowering plasma glucose levels. In this article, we will review the effect of diabetes in the pathobiology of atherosclerosis, molecular and vascular biology of TZDs, as well as the clinical imaging studies looking at progression or regression of atherosclerosis in patients treated with glitazones.

\section{Pathobiology of atherosclerosis}

Mechanisms leading to increased atherosclerotic risk in patients with diabetes continue to be discovered. Obesity frequently precedes the development of insulin resistance and diabetes. ${ }^{7}$ High fat diets in animal models potentiate endothelial derived contracting factor (EDCF) mediators leading to the formation of increased levels of free radicals and pronounced up regulation of vascular thromboxane prostanoid receptor gene. These two changes weaken the protective role of the endothelium with reduced nitric oxide production and enhanced responsiveness to endothelin. ${ }^{8,9,10}$ Summarizing these findings, Traupe et al advocate that obesity related increases in production of EDCFs may contribute to the development of vascular diseases. As insulin resistance advances and patients develop diabetes, comparable vascular abnormalities are present at the endothelial level ${ }^{11,12}$ (see Figure 1).

Subjects with type 2 diabetes mellitus are at high risk for the development of atherosclerosis. An essential event in the growth of atherosclerosis is macrophage foam cell formation. Burke et al studied the morphology of diabetes plaques postmortem and found a strong positive association of increased macrophage infiltrate that was independent of cholesterol levels and patient age. ${ }^{13}$ The necrotic core size or macrophage infiltrate was significantly increased in diabetic subjects compared to nondiabetics with or without hyperlipidemia $(P<0.002)$. In addition, the removal of cholesterol by macrophages plays a vital role in macrophage foam cell. Mauldin et al studied blood samples collected from diabetes patients for regulation of cholesterol efflux by ATP-binding cassette $(\mathrm{ABC})$ transporters $\mathrm{ABCA} 1$ and ABCG1. Macrophages from subjects with type 2 diabetes mellitus had a $30 \%$ 
diminution in cholesterol efflux to high density lipoprotein (HDL) or Apo A1 with an analogous 60\% increase in cholesterol accumulation relative to control subjects. This reduction in cholesterol efflux in type 2 diabetes patients is additive to the already amplified risk of atherosclerosis.

Intravascular ultrasound studies (IVUS) from Hong et al found that diabetes patients presenting with acute coronary syndrome (ACS), had a higher incidence of multiple plaque ruptures ( $60 \%$ vs $29 \%$ non-diabetes, $P<0.001)$ and thrombus $(72 \%$ vs $52 \%$ non-diabetes, $P<0.032$ ) by IVUS than non-diabetes patients. A significant correlation with increased necrotic core volumes and thin cap fibroatheroma in the diabetes subset. ${ }^{14}$

Basic research is very important and its ties to clinical practice always are highly sought after. Recently, the ATHEROMA trial studied macrophages using iron oxide in humans given atorvastatin. ${ }^{15}$ Historically, increases in macrophage infiltration increase the risk of plaque rupture consequently detecting macrophage activity and inflammation within the atheroma could help discriminate stable plaque from vulnerable plaques. To evaluate macrophage activity, Tang et al randomized 47 patients with carotid stenosis by carotid ultrasound who had plaque accumulation on MRI to atorvastatin $10 \mathrm{mg}$ or $80 \mathrm{mg}$ for 12 weeks. The primary end point definition was a change from baseline in signal intensity on the ultrasmall superparamagnetic iron-oxide-(USPIO)enhanced MRI. Twenty patients completed the study, finding a significant reduction from baseline in signal intensity, the USPIO-enhanced MRI definition of plaque inflammation, in the high-dose atorvastatin arm at 6 and 12 weeks, while the patients treated with atorvastatin $10 \mathrm{mg}$ showed no significant difference. This type of research is extremely important to further understanding of types of treatments that may regress plaque and reduce clinical events.

In summary, histology, metabolic changes and imaging studies all point toward a much higher risk for atherosclerosis development and CVD risk in patients with diabetes.

\section{Molecular and vascular biology of glitazones}

By definition the TZDs (glitazones) act by binding to peroxisome proliferator-activated receptors (PPARs), a group of receptor molecules inside the cell nucleus, specifically PPAR $\gamma / \alpha / \beta / \delta$. The ligands for these receptors are free fatty acids (FFAs) and eicosanoids. When activated, the receptor migrates to the DNA, activating transcription of a number of specific genes. These nuclear changes have far reaching affects on metabolic status in patients. Issemann and Green discovered the mechanism by which peroxisome proliferation in the liver was induced by hypolipidemic drugs. ${ }^{16}$ The discovery of this mechanism in 1990 led to the rapid development of many compounds in an attempt to improve the metabolic profile of primarily diabetes patients (Figure 2).

In general PPAR $\alpha$ agonist (fibrates) improved the dyslipidemic profile in patients by lowering triglycerides (TG) and increasing HDL. Unfortunately, large pivotal trails (Fenofibrate Intervention and Event Lowering in Diabetes (FIELD)) did not demonstrate positive primary endpoints, although secondary cardiovascular endpoints were more favorable. ${ }^{17}$ Fenofibrate failed to significantly reduce the risk of the primary outcome, coronary events. It did reduce total cardiovascular events, mainly due to fewer non-fatal myocardial infarctions and revascularizations. The placebo arm had an increased rate of statin initiation, which might have masked a moderately larger treatment benefit.

Other basic science studies have found that fibrates could increase plasma homocysteine levels that occur through a PPAR $\alpha$-dependent mechanism and could reduce hepatic apo-AI production, by decreasing PPAR $\alpha$ activity. ${ }^{18,19}$ On the contrary other indirect beneficial effects of PPAR $\alpha$ are suggestive from pioglitazone in the PROactive ${ }^{36}$ and PERISCOPE studies that demonstrated increases in HDL with reduction in triglycerides. ${ }^{20}$ In a head-to-head clinical trial and metaanalysis, pioglitazone decreased TG significantly while this was not seen with rosiglitazone. ${ }^{21,22}$ Recently reported, pioglitazone increased IkBa expression in a PPAR $\alpha$-dependent manner potentially increasing expression of PPAR $\alpha$ target genes in subcutaneous fat. ${ }^{23,24}$ Rosiglitazone had no effects on PPAR $\alpha$ activation. ${ }^{22}$ However rosiglitazone has shown a reduction in restenosis after coronary artery stenting and MMP-9 in type 2 diabetes patients..$^{25,26}$

PPAR gamma ligands (thiazolidinediones (TZDs)) are the primary drugs used in type 2 diabetes for improving insulin sensitivity in skeletal muscle. The beneficial effects of TZDs on insulin sensitization effects are via the activation of PPAR $\gamma$ in adipose tissue, resulting in improved insulin sensitivity in skeletal muscle and liver. Human studies support PPAR $\gamma$ mRNA expression in human skeletal muscle is acutely regulated by insulin and is augmented in both obese non-diabetes and type II diabetes subjects in direct relation to BMI and fasting insulin levels. ${ }^{27}$ These abnormalities of PPAR $\gamma$ are in part involved in skeletal muscle insulin resistance of obesity and type II diabetes. PPAR $\gamma$ induces subcutaneous adipocyte differentiation and reduces the visceral-to-subcutaneous adipose tissue ratio, which help to store free fatty acids in a less harmful subcutaneous location. 


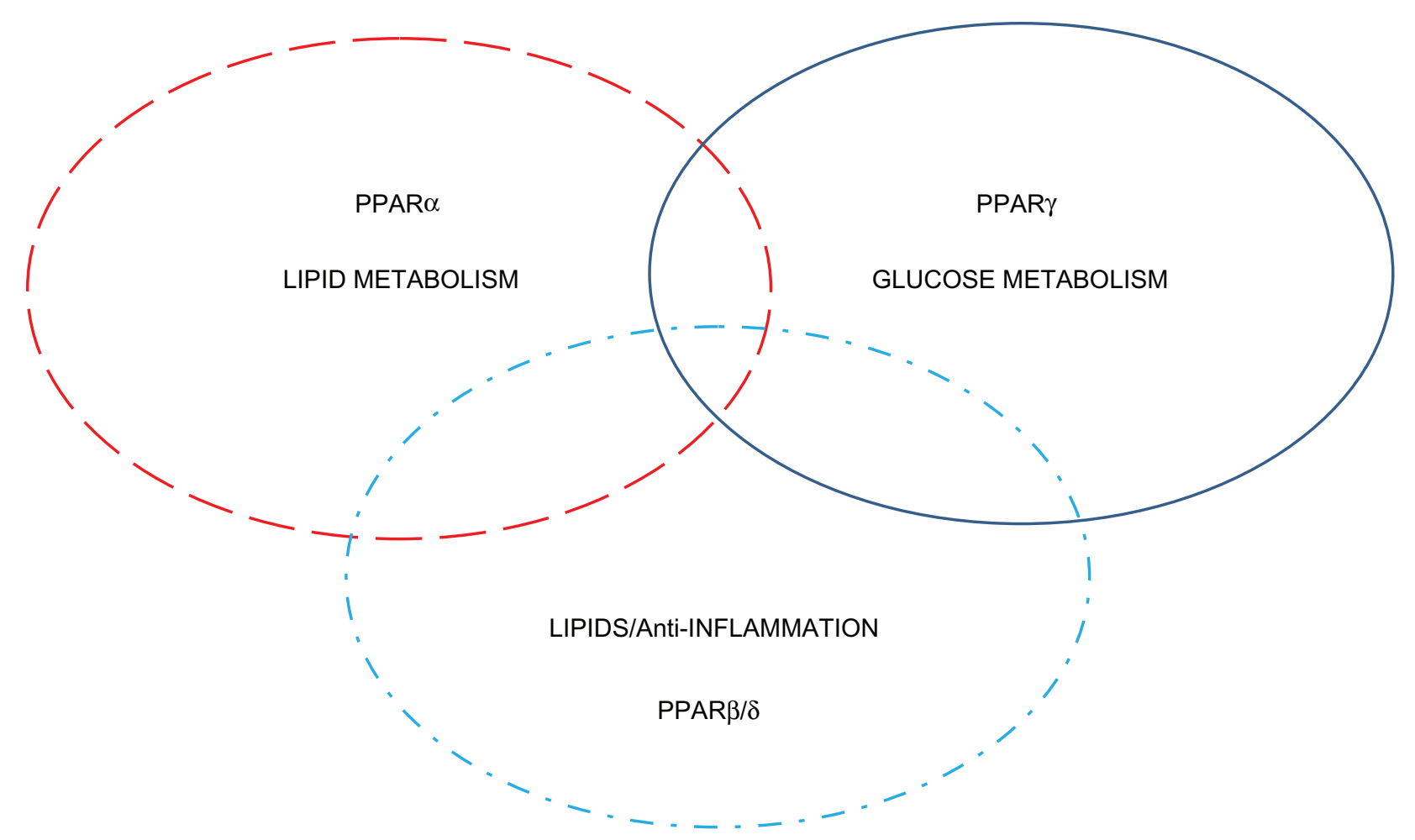

Figure 2 Peroxisome proliferative activated receptors (PPARs) clinical overview. This figure shows the overlapping activity of the PPARs. Clinically the current glucose-lowering agents and insulin sensitizers are PPAR $\gamma$. PPAR $\alpha$ compounds are primarily fibrates that reduce triglyceride levels and increase high-density lipoprotein cholesterol. PPAR $\beta / \delta$ is still experimental.

$\operatorname{PPAR} \beta / \delta$ is a new exciting area of research. This PPAR isoform has only recently been studied because of its ubiquitous nature. Its major efforts are focused in lipid uptake and anti-inflammatory roles. In several animal models of obesity and diabetes, these compounds increase HDL cholesterol and decrease white adipose tissue fat deposits. They have been found to reduce triglycerides, small dense LDL, and improve fasting insulin. ${ }^{28,29}$

In summary, in vitro research suggests that PPARs exert anti-atherogenic effects by inhibiting the expression of proinflammatory genes and enhancing cholesterol efflux via activation of the liver X receptor-ABCA1 (LXR-ABCA1) pathway. Foam cell formation is a major therapeutic target in atherosclerosis. Basic cell research by Li et al found that PPAR $\alpha$ and PPAR $\gamma$ agonists inhibited foam-cell formation in vivo through distinct ABCA1-independent pathways with stimulation of HDL cholesterol efflux. ${ }^{30}$ These findings from basic science would suggest a clinical benefit of TZDs in reducing atherosclerosis.

\section{Glitazones and CV imaging of atherosclerosis}

There are few things that influence humans more than a good illustrative picture. IVUS or imaging of the human coronary for atherosclerosis is probably very similar. One of the most impressive changes that come to mind is the research trial REVERSAL. The trial evaluated intensive lipid-lowering treatment (atorvastatin) vs moderate lipid-lowering regimen (pravastatin). The primary end point of the REVERSAL study was percent change in atheroma volume, which showed a $2.7 \%$ significant increase in the pravastatin group and a $0.4 \%$ nonsignificant reduction in the atorvastatin group $(P<0.02)$. This changed, to a large degree, many physicians view of statins in atherosclerosis treatment. The visual impact from the IVUS image was very impressive.

Studies with the glitazones are equally impressive. The studies to follow are completed in patients with type 2 diabetes who are considered as a coronary heart disease risk equivalent.

An important factor in the trials to follow is that in most of these trials patients were on statins and antiplatelet agents representative of the current high level of cardiovascular and diabetes care. The addition of the glitazones to these patients already on maximal cardiovascular treatment will be important when considering the results.

PERISCOPE was one of the first large randomized landmark glitazones IVUS trials. It enrolled 543 patients with type 2 diabetes who had baseline IVUS of the coronary 
artery and then were randomized to receive either glimepiride (1-4 mg) or pioglitazone (15-45 mg) for 18 months, at which time IVUS studies were repeated. The primary endpoint found that the mean percent atheroma volume decreased by $0.16 \%$ in pioglitazone-treated subjects but increased by $0.73 \%$ in glimepiride-treated patients. The use of statins in this trial was greater than $80 \%$ with $90 \%$ aspirin use. Both agents reduced $\mathrm{HbA}_{1 \mathrm{c}}$ and fasting insulin levels, although pioglitazone's effects on these end points were statistically greater. Pioglitazone also produced statistically beneficial changes in HDL and TG levels. In the pioglitazone group, compared with glimepiride, HDL levels increased $5.7 \mathrm{mg} / \mathrm{dL}$ (95\% CI, 4.4 to $7.0 \mathrm{mg} / \mathrm{dL} ; 16.0 \%)$ vs $0.9 \mathrm{mg} / \mathrm{dL}(95 \%$ CI, -0.3 to $2.1 \mathrm{mg} / \mathrm{dL} ; 4.1 \%$ ), and median TG levels decreased $16.3 \mathrm{mg} / \mathrm{dL}$ (95\% CI, -27.7 to $-11.0 \mathrm{mg} / \mathrm{dL} ; 15.3 \%) \mathrm{vs}$ an increase of $3.3 \mathrm{mg} / \mathrm{dL}(95 \% \mathrm{CI},-10.7$ to $11.7 \mathrm{mg} / \mathrm{dL} ; 0.6 \%)$ $(P<0.001$ for both comparisons $) .{ }^{31}$

APPROACH randomized 672 patients with type 2 diabetes and indications for coronary angiography or PCI, at least 1 clinically significant coronary lesion, and 10\% to $50 \%$ narrowing of at least 1 untreated coronary artery. 333 were randomized to rosiglitazone at up to $8 \mathrm{mg}$ /day and 339 patients who received glipizide at $15 \mathrm{mg} /$ day. Aspirin use was about $84 \%$, beta blockers in $67 \%$, angiotensin-converting enzyme (ACE) inhibitors or angiotensin-receptor blockers in about $74 \%$, and statins in about $80 \%$. The primary analysis from baseline to 18 months follow up found the percent atheroma volume was not significantly different between the treatment groups. A decrease of atheroma volume was seen by $-0.21 \%$ in rosiglitazone-treated subjects with an increase by $+0.43 \%$ in glipizide-treated patients $(P=0.12)$. Hypoglycemia was more common the glipizide arm $28 \%$ vs $8 \%$ with rosiglitazone $(P<0.0001)$. In summary, the primary endpoint was unremarkable, however the results imply that rosiglitazone could be antiatherosclerotic but it did not appear to be proatherosclerotic. ${ }^{32,33}$

What accounts for the difference between these two imaging trials is unclear at present. Metabolics of the two compounds are different in relation to HDL and triglycerides from Goldberg et al and may affect plaque biology. ${ }^{34}$ The comparative drugs used in the trial are different and the duration of diabetes is different (see Figure 3 and Table 1). The anti-inflammatory aspects could play a role but at present there is no clear explanation why the results were different. Two different IVUS control labs were used, both very well known with high quality work. Amount of atherosclerotic burden and type of plaque biology could be different but unknown at present. Longstanding prior statin treatment in some groups may have already reduced soft plaque that more easily is removed. More basic research on plaque biology is required. Another important comment concerning these two trials is a possible lack of significant difference between the rosiglitazone and comparator in the APPROACH was due to a better outcome in the group treated with comparator (glipizide), as opposed to the effect observed in PERISCOPE, where the group treated with glimepiride fared worse. The mean percent atheroma volume decrease $0.16 \%$ with pioglitazone and $0.21 \%$ with rosiglitazone appear rather comparable. It should be noted that in PERISCOPE glimeperide increased it by $0.73 \%$ while in APPROACH glipizide increased it only $0.43 \%$. Thus it is possible for the difference between the two studies was in the different effects of the comparator drugs rather than the TZDs.

Other considerations of vascular imaging of the human carotid are helpful in evaluation of atherosclerosis. Two large trials related to the glitazones have been completed.

The most recent study reported was involving patients with pre-diabetes but without clinical evidence for CVD. STARR (STudy of Atherosclerosis with Ramipril and Rosiglitazone), a sub-study of the DREAM (Diabetes REduction Assessment with ramipril and rosiglitazone Medication) trial with 1425 subjects intended at assessing the effects of the ACE inhibitor ramipril and the TZD rosiglitazone on the progression of carotid intima-media thickness (CIMT). Using a $2 \times 2$ factorial design subjects were randomized to ramipril $15 \mathrm{mg} /$ day or its placebo and to rosiglitazone $8 \mathrm{mg}$ /day or its placebo. The primary study outcome was the annualized change of the aggregate maximum CIMT, computed as the average of the maximum CIMTs across 12 carotid arterial segments. A secondary endpoint of annualized change of the mean far wall left and right common CIMT. Median follow-up was 3 years and carotid ultrasound examinations were obtained at baseline and yearly thereafter. Rosiglitazone decreased glycemia with a mild reduction in blood pressure and modest favorable effects on CIMT progression. Compared with placebo, rosiglitazone reduced the primary CIMT outcome, but the difference was not statistically significant. The primary outcome aggregate maximum CIMT was $0.00063 \mathrm{~mm} /$ year for the rosiglitazone arm and $0.0090 \mathrm{~mm} /$ year for placebo (difference $-0.0027 P=0.08$ ).

The CHICAGO study was a randomized, double-blind, comparator-controlled trial from the Chicago metropolitan area at 28 clinical sites. 462 patients with type 2 diabetes were randomized to receive 72 weeks of treatment with pioglitazone, or glimepiride, titrated to the $\mathrm{HbA}_{1 \mathrm{c}}$ target. Patients had a mean duration of diabetes of 7.7 years and 


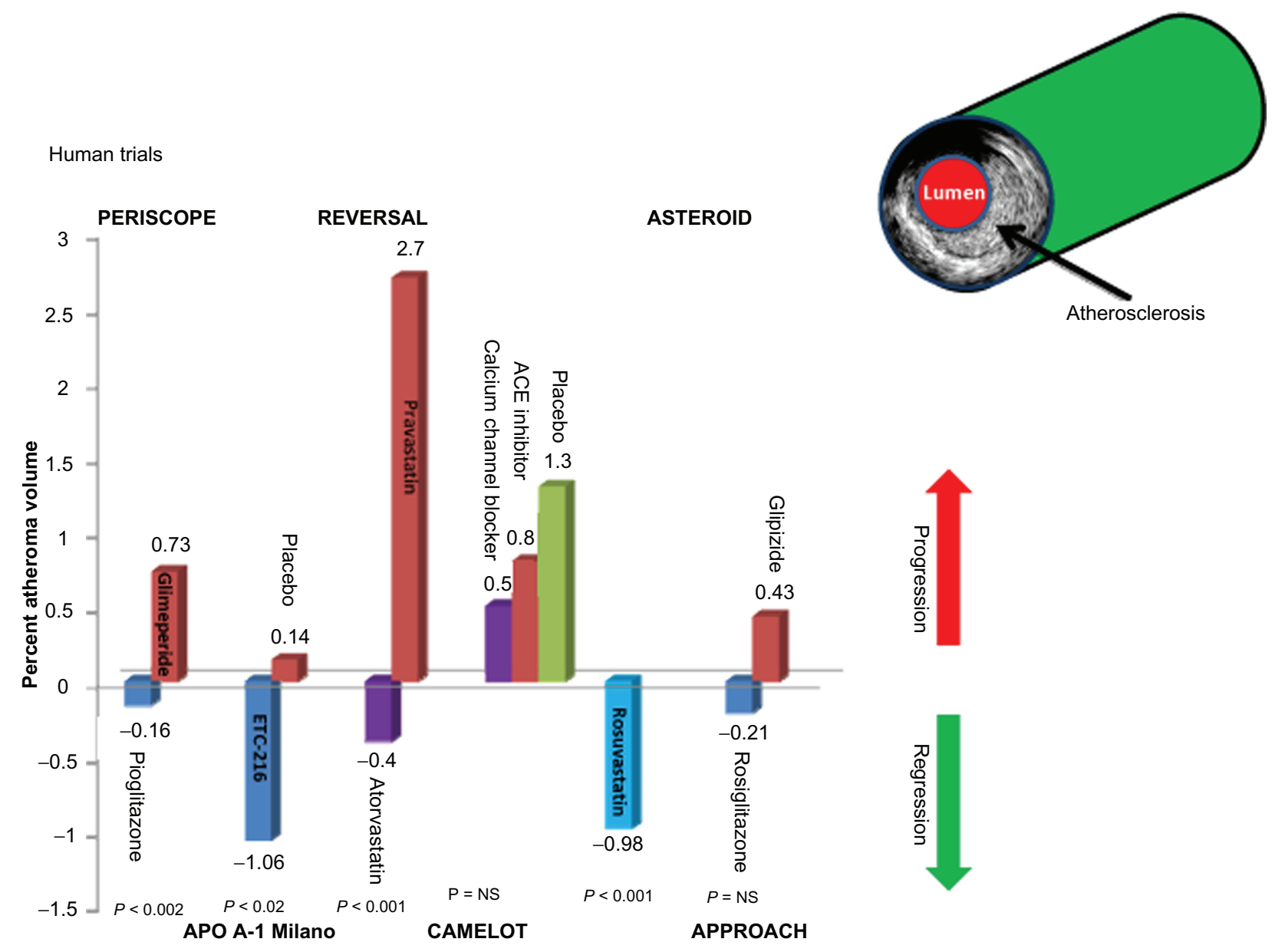

Figure 3 Intravascular ultrasound studies change from baseline in percent atheroma volume.

a mean $\mathrm{HbA}_{1 \mathrm{c}}$ value of $7.4 \% .55 \%$ of both groups were receiving statins. CIMT images were captured by a single ultrasonographer at one center and read by a single reader blinded to treatment assignment using automated edgedetection technology. The main outcome measure was the absolute change from baseline to the final visit at 72 weeks in the mean posterior-wall CIMT of the left and right common carotid arteries. The results found the CIMT was less with pioglitazone than it was with glimepiride at all time points - weeks 24,48 , and 72 . The primary end point of progression of mean CIMT was less with pioglitazone, with a difference between groups of $0.013 \mathrm{~mm}$, favoring the pioglitazone group $(95 \% \mathrm{CI}-0.013$ [ -0.024 to 0.002$]$; $P<0.02){ }^{35}$

Table I Trial demographics and imaging results

\begin{tabular}{|c|c|c|c|c|c|c|c|}
\hline Trial & ACS & Chronic CAD & DM & ASA & Statin & Results & Comment \\
\hline ASTEROID-IVUS & & $\sqrt{ }$ & & $>80 \%$ & Rosuvastatin $40 \mathrm{mg}$ & ++++ & No comparator arm \\
\hline PERISCOPE-IVUS & & & $\sqrt{ }$ & $>90 \%$ & $>80 \%$ & +++ (Pioglitazone) & $\begin{array}{l}\text { Glimepiride vs } \\
\text { Pioglitazone }\end{array}$ \\
\hline REVERSAL-IVUS & & $\sqrt{ }$ & & & $32 \%$ & $++($ Atorvastatin 80$)$ & $\begin{array}{l}\text { Atorvastatin } 80 \text { vs } \\
\text { Pravastatin } 40\end{array}$ \\
\hline ApoAI Milano-IVUS & $\sqrt{ }$ & & & & $\begin{array}{l}30 \% \text { placebo } \\
50 \% \text { ETC- } 216\end{array}$ & ++++ & \\
\hline APPROACH-IVUS & & & $\sqrt{ }$ & & & $P=\mathrm{NS}$ & $\begin{array}{l}\text { Rosiglitazone vs } \\
\text { Glipizide }\end{array}$ \\
\hline
\end{tabular}

Abbreviations: ACS, acute coronary syndrome; ASA, aspirin; CAD, coronary artery disease; DM, diabetes mellitus; IVUS, intravascular ultrasound. 
The CIMT results between STARR and CHICAGO are different. The types of patients are different between these two studies, CHICAGO used type 2 diabetes patients and STARR was pre-diabetes patients. Use of other medication may impact the results and drug combinations choices can affect plaque biology. The consistent beneficial findings with pioglitazone from PERISCOPE and CHICAGO merits a closer look at this type of TZD. The inconsistency from rosiglitazone in the trials is disturbing; however the trials are different in design, patient characteristics, and drug combinations used. All of these differences make it very hard to make strong statements or recommendations.

In summary, imaging trials are not perfect for answering many of our questions concerning glitazones in patients with pre-diabetes or type 2 diabetes. Most importantly they do not fully answer the main question: do they reduce cardiovascular clinical events, or regression of atherosclerosis will remain unanswered for now, requiring future studies. In closing two large studies have attempted to answer the cardiovascular question related to glitazones. PROactive trial ${ }^{36}$ enrolled 5238 patients with type 2 diabetes who had evidence of macrovascular disease in a prospective, randomized study. The primary endpoint included a composite of endovascular or surgical intervention in the coronary or leg arteries, and amputation above the ankle, all-cause mortality, non-fatal myocardial infarction (including silent myocardial infarction), stroke, acute coronary syndrome. The primary endpoint was not met (hazard ratio $0.90,95 \%$ CI $0.80-1.02, P=0.095$ ) primarily due to leg revascularization. The principle secondary endpoint was a composite of all-cause mortality, non-fatal myocardial infarction, and stroke $(0.84,0.72-0.98, P=0.027)$. This study has been one of the most controversial studies related to TZDs and still is unresolved from main points of view. Many of the sub-studies are very positive toward pioglitazone, with consistent trends in a favorable direction; however the primary study missed its endpoint. On the heels of this large TZD trial is RECORD,${ }^{37}$ which was a multicenter, open-label trial, in which 4447 patients with type 2 diabetes on metformin or sulfonylurea monotherapy with mean $\mathrm{HbA}_{1 \mathrm{c}}$ of $7.9 \%$ were randomly assigned to addition of rosiglitazone $(n=2220)$ or to a combination of metformin and sulfonylurea (active control group, $\mathrm{n}=2227$ ). The primary endpoint was cardiovascular hospitalization or cardiovascular death, with a hazard ratio non-inferiority margin of 1.20. Analysis was by intention to treat. The primary outcome during a mean 5.5-year follow-up, met non-inferiority criteria (hazard ratio $0.99,95 \%$ CI $0.85-1.16)$. Specific to cardiovascular death the HR was 0.84 (0.59-1.18), and for myocardial infarction was $1.14(0.80-1.63)$, and $0.72(0.49-1.06)$ for stroke. Both of these trials reported increased heart failure concerns and bone fractures that made things even more difficult with these compounds. Currently, the controversy still continues to be a hotly debated topic on both sides and unlikely to be resolved in time.

In closing, the future is bright for many other imaging modalities from research that have not been included due to the current studies did not use this type of equipment. For imaging from inside the coronary tree, the current resolution of IVUS is around 150 microns; however soon, with radiolabeling, the use of optical coherence tomography at 5 microns may offer substantial advantage to our understanding of atherosclerosis. ${ }^{38}$

\section{Disclosures}

RC lectures for Pfizer, Takeda, GSK and MSD. The other authors declare no conflicts of interest.

\section{References}

1. Narayan KM, Boyle JP, Geiss LS, Saaddine JB, Thompson TJ. Impact of recent increase in incidence on future diabetes burden: US, 2005-2050. Diabetes Care. 2006;29(9):2114-2116.

2. Fox CS, Pencina MJ, Wilson PW, Paynter NP, Vasan RS, D’Agostino RB Sr. Lifetime risk of cardiovascular disease among individuals with and without diabetes stratified by obesity status in the Framingham heart study. Diabetes Care. 2008;31(8):1582-1584.

3. Narayan KM, Boyle JP, Thompson TJ, Gregg EW, Williamson DF. Effect of BMI on lifetime risk for diabetes in the US Diabetes Care. 2007;30(6):1562-1566.

4. Juutilainen A, Lehto S, Rönnemaa T, Pyörälä K, Laakso M. Similarity of the impact of type 1 and type 2 diabetes on cardiovascular mortality in middle-aged subjects. Diabetes Care. 2008;31(4):714-719.

5. Whiteley L, Padmanabhan S, Hole D, Isles C. Should diabetes be considered a coronary heart disease risk equivalent?: results from 25 years of follow-up in the Renfrew and Paisley survey. Diabetes Care. 2005;28(7):1588-1593.

6. Goraya TY, Leibson CL, Palumbo PJ, et al. Coronary atherosclerosis in diabetes mellitus: a population-based autopsy study. J Am Coll Cardiol. 2002;40(5):946-953.

7. Xiang L, Dearman J, Abram SR, Carter C, Hester RL. Insulin resistance and impaired functional vasodilation in obese Zucker rats. Am J Physiol Heart Circ Physiol. 2008;294(4):H1658-H666.

8. Traupe T, D’Uscio LV, Muenter K, Morawietz H, Vetter W, Barton M. Effects of obesity on endothelium-dependent reactivity during acute nitric oxide synthase inhibition: modulatory role of endothelin. Clin Sci (Lond). 2002;103 Suppl 48:13S-15S.

9. Traupe T, Lang M, Goettsch W, et al. Obesity increases prostanoidmediated vasoconstriction and vascular thromboxane receptor gene expression. J Hypertens. 2002;20(11):2239-2245.

10. Gollasch M. Endothelium-derived contracting factor: a new way of looking at endothelial function in obesity. J Hypertens. 2002;20(11):2147-2149.

11. Shi Y, So KF, Man RY, Vanhoutte PM. Oxygen-derived free radicals mediate endothelium-dependent contractions in femoral arteries of rats with streptozotocin-induced diabetes. Br J Pharmacol. 2007;152(7):1033-1041.

12. Tesfamariam B, Brown ML, Cohen RA. Elevated glucose impairs endothelium-dependent relaxation by activating protein kinase $\mathrm{C}$. J Clin Invest. 1991;87(5):1643-1648. 
13. Burke AP, Kolodgie FD, Zieske A, et al. Morphologic findings of coronary atherosclerotic plaques in diabetics:a postmortem study. Arterioscler Thromb Vasc Biol. 2004;24(7):1266-12671.

14. Hong YJ, Jeong MH, Choi, et al. Plaque characteristics in culprit lesions and inflammatory status in diabetic acute coronary syndrome patients. JACC Cardiovasc Imaging. 2009;2(3):339-349.

15. Tang TY, Howarth SP, Miller SR, et al. The ATHEROMA (Atorvastatin Therapy: Effects on Reduction of Macrophage Activity) Study. Evaluation using ultrasmall superparamagnetic iron oxide-enhanced magnetic resonance imaging in carotid disease. J Am Coll Cardiol. 2009;253(22):2039-20350.

16. Issemann I, Green S. Activation of a member of the steroid hormone receptor superfamily by peroxisome proliferators. Nature. 1990;347(6294):645-650.

17. Keech A, Simes RJ, Barter P, et al; FIELD study investigators. Effects of long-term fenofibrate therapy on cardiovascular events in 9795 people with type 2 diabetes mellitus (the FIELD study): randomised controlled trial. Lancet. 2005;366(9500):1849-1861. Erratum in: Lancet. 2006;368(9545):1415. Lancet. 2006;368(9545):1420.

18. de Lorgeril M, Salen P, Paillard F, Lacan P, Richard G. Lipid-lowering drugs and homocysteine. Lancet. 1999;353(9148):209-210.

19. Mikael LG, Genest J Jr, Rozen R. Elevated homocysteine reduces apolipoprotein A-I expression in hyperhomocysteinemic mice and in males with coronary artery disease. Circ Res. 2006;98(4):564-571.

20. Nissen SE, Nicholls SJ, Wolski K, et al; PERISCOPE Investigators. Comparison of pioglitazone vs glimepiride on progression of coronary atherosclerosis in patients with type 2 diabetes: the PERISCOPE randomized controlled trial. JAMA. 2008;299(13):1561-15073.

21. Chiquette E, Ramirez G, Defronzo R. A meta-analysis comparing the effect of thiazolidinediones on cardiovascular risk factors. Arch Intern Med. 2004;164(19):2097-2104.

22. Goldberg RB, Kendall DM, Deeg MA, et al; GLAI Study Investigators. A comparison of lipid and glycemic effects of pioglitazone and rosiglitazone in patients with type 2 diabetes and dyslipidemia. Diabetes Care. 2005;28(7):1547-1554.

23. Orasanu G, Ziouzenkova O, Devchand PR, et al. The peroxisome proliferator-activated receptor-gamma agonist pioglitazone represses inflammation in a peroxisome proliferator-activated receptoralpha-dependent manner in vitro and in vivo in mice. J Am Coll Cardiol. 2008;52(10):869-881.

24. Bogacka I, Xie H, Bray GA, Smith SR. The effect of pioglitazone on peroxisome proliferator-activated receptor-gamma target genes related to lipid storage in vivo. Diabetes Care. 2004;27(7):1660-1667.

25. Osman A, Otero J, Brizolara A, et al. Effect of rosiglitazone on restenosis after coronary stenting in patients with type 2 diabetes. Am Heart J. 2004;147(5):e23.

26. Marx N, Froehlich J, Siam L, et al. Antidiabetic PPAR gamma-activator rosiglitazone reduces MMP-9 serum levels in type 2 diabetic patients with coronary artery disease. Arterioscler Thromb Vasc Biol. $2003 ; 23(2): 283-288$.
27. Park KS, Ciaraldi TP, Abrams-Carter L, Mudaliar S, Nikoulina SE, Henry RR. PPAR-gamma gene expression is elevated in skeletal muscle of obese and type II diabetic subjects. Diabetes. 1997;46(7): 1230-1234.

28. Berger J, Leibowitz MD, Doebber TW, et al. Novel peroxisome proliferator-activated receptor (PPAR) gamma and PPARdelta ligands produce distinct biological effects. J Biol Chem. 1999; 274(10):6718-6725.

29. Oliver WR Jr, Shenk JL, Snaith MR, et al. A selective peroxisome proliferator-activated receptor delta agonist promotes reverse cholesterol transport. Proc Natl Acad Sci U S A. 2001;98(9):5306-5311.

30. Li AC, Binder CJ, Gutierrez A, et al. Differential inhibition of macrophage foam-cell formation and atherosclerosis in mice by PPARalpha,beta/delta, and gamma. J Clin Invest. 2004;114(11): 1564-1576.

31. Nissen SE, Nicholls SJ, Wolski K, et al; PERISCOPE Investigators. Comparison of pioglitazone vs glimepiride on progression of coronary atherosclerosis in patients with type 2 diabetes: the PERISCOPE randomized controlled trial. JAMA. 2008;299(13):1561-1573.

32. Ratner RE, Cannon CP, Gerstein HC, et al; APPROACH Study Group. Assessment on the Prevention of Progression by Rosiglitazone on Atherosclerosis in diabetes patients with Cardiovascular History (APPROACH): study design and baseline characteristics. Am Heart J. 2008;156(6):1074-1079.

33. Nesto RW. Assessment on the Prevention of Progression by Rosiglitazone on Atherosclerosis in Type 2 Diabetes patients with Cardiovascular History (APPROACH). American Heart Association 2008 Scientific Sessions; November 12, 2008; New Orleans, LA. Late Breaking Clinical Trials Session 4.

34. Goldberg RB, Kendall DM, Deeg MA, et al; GLAI Study Investigators. A comparison of lipid and glycemic effects of pioglitazone and rosiglitazone in patients with type 2 diabetes and dyslipidemia. Diabetes Care. 2005;28(7):1547-1554.

35. Mazzone T, Meyer PM, Feinstein SB, et al. Effect of pioglitazone compared with glimepiride on carotid intima-media thickness in type 2 diabetes: a randomized trial. JAMA. 2006;296(21):2572-2581.

36. Dormandy JA, Charbonnel B, Eckland EJA, et al. Secondary prevention of macrovascular events in patients with type 2 diabetes: a randomized trial of pioglitazone. The PROactive Study (PROspective pioglitAzone Clinical Trial In macroVascular Events). Lancet. 2005;366(9493):1279-1289.

37. Home PD, Pocock SJ, Beck-Nielsen H, et al. Rosiglitazone evaluated for cardiovascular outcomes in oral agent combination therapy for type 2 diabetes (RECORD): a multicentre, randomized, open-label trial. Lancet. 2009;373(9681):2125-2135.

38. Villard JW, Paranjape AS, Victor DA, Feldman MD. Applications of optical coherence tomography in cardiovascular medicine. $\mathrm{J} \mathrm{Nucl}$ Cardiol. 2009;16(4):620-639.
Vascular Health and Risk Management

\section{Publish your work in this journal}

Vascular Health and Risk Management is an international, peerreviewed journal of therapeutics and risk management, focusing on concise rapid reporting of clinical studies on the processes involved in the maintenance of vascular health; the monitoring, prevention and treatment of vascular disease and its sequelae; and the involvement of

\section{Dovepress}

metabolic disorders, particularly diabetes. This journal is indexed on PubMed Central and MedLine. The manuscript management system is completely online and includes a very quick and fair peer-review system, which is all easy to use. Visit http://www.dovepress.com/ testimonials.php to read real quotes from published authors. 